BULLETIN Bulletin hispanique

HISPANIQUE Université Michel de Montaigne Bordeaux

$114-2$ | 2012

Varia

\title{
Alain Sicard, El mar y la ceniza, Nuevas aproximaciones a la poesía de Pablo Neruda
}

Éditions LOM, Santiago de Chile, 2011

Bénédicte Mathios

\section{CpenEdition}

\section{Journals}

Édition électronique

URL : https://journals.openedition.org/bulletinhispanique/2295

DOI : 10.4000/bulletinhispanique.2295

ISSN : $1775-3821$

\section{Éditeur}

Presses universitaires de Bordeaux

Édition imprimée

Date de publication : 31 décembre 2012

Pagination : $967-970$

ISBN : 978-2-86781-855-4

ISSN : 0007-4640

\section{Référence électronique}

Bénédicte Mathios, «Alain Sicard, El mar y la ceniza, Nuevas aproximaciones a la poesía de Pablo

Neruda », Bulletin hispanique [En ligne], 114-2 | 2012, mis en ligne le 23 juillet 2013, consulté le 30 juillet 2022. URL : http://journals.openedition.org/bulletinhispanique/2295 ; DOI : https://doi.org/10.4000/ bulletinhispanique.2295

Ce document a été généré automatiquement le 30 juillet 2022

Tous droits réservés 


\section{Alain Sicard, El mar y la ceniza, Nuevas aproximaciones a la poesía de Pablo Neruda}

Éditions LOM, Santiago de Chile, 2011

\section{Bénédicte Mathios}

\section{RÉFÉRENCE}

Alain Sicard, El mar y la ceniza, Nuevas aproximaciones a la poesía de Pablo Neruda. Santiago de Chile, éditions LOM, 2011, 219 p. - ISBN : 978-956-00-0259-4

1 Le livre d'Alain Sicard, intitulé El mar y la ceniza, Nuevas aproximaciones a la poesía de Pablo Neruda, qu'ont publié en 2011 les éditions LOM à Santiago de Chile, nous offre le cheminement de ce grand spécialiste de l'œuvre nérudienne vers une approche toujours plus libre du monument de la littérature chilienne du XXe siècle qu'est l'œuvre de Pablo Neruda, que nous connaissons tous de manière plus ou moins complète, selon nos propres parcours, formations, générations...

2 Un avant-propos nous éclaire sur le projet : bien loin d'une biographie factuelle, le livre proposé à notre lecture, d'un abord aisé, d'un style limpide, nous montre, par diverses approches (tour à tour essayiste, agréablement didactique, fragmentée, lyrique, narrative), manifestées par divers articles réunis en cinq grandes sections ( El Yo nerudiano", "Poéticas", «Lecturas cruzadas", " Navegaciones y regresos", «Variaciones en torno a dos poemas »), le rayonnement d'une écriture vers la vie. Ces analyses enrichissent et clarifient tout à la fois les lectures que tout un chacun peut faire aujourd'hui de cette œuvre majeure $\mathrm{du} \mathrm{XX}^{\mathrm{e}}$ siècle, aux résonnances encore actuelles, voire, pour certains de ses aspects, intemporelles. 


\section{Portraits}

Les trois facettes du moi nérudien que dessine un premier groupe d'essais, configurent un portrait où le lecteur assidu de l'œuvre poétique de Pablo Neruda reconnaîtra certains traits, finement rappelés par l'auteur de La pensée poétique de Pablo Neruda et de Pablo Neruda: une utopie poétique, ainsi par exemple la conjonction de la lumière et de l'ombre antithétiques, dans une utopie totalisatrice dont le maître-mot est la mort omniprésente, au sein de laquelle le moi poétique «sitúa [...] el fundamento de todo conocimiento » (p. 22). La facette ambiguë de l'envie comme " envés de [la] solidaridad entre los hombres» (p.37) participe également de ce portrait, et interroge le sujet poétique, tour à tour arbre ou semence, dans tous les cas expansion, et dont la parole évite la polémique au profit de la réflexion. Le troisième volet qui complète le portrait nérudien, "El Yo nerudiano", tend à faire tomber tous les préjugés : voilà un moi inévitable («insoslayable», p. 39), mais pas seulement par égocentrisme; en effet, la question de l'identité, puis de l'identification au monde, matériel et humain (par plongée dans la matière et par expansion, de nouveau) ne cessent de se poser jusqu'à la fin de l'œuvre : «El Yo nerudiano de los veinte últimos años es un Yo que no solamente asume su contradicción existencial (« ser y no ser resultan ser la vida »), sino que hace de ella la base de su relación con el mundo, y, en primer lugar, con la historia » (p. 48). Ainsi, concernant la figure du poète, rien n'est tranché par une vision manichéenne ou simplement idéologique, ce que démontre le critique dans ces travaux.

\section{Poétiques}

Il est également frappant de voir que la section suivante s'intitule au pluriel "Poéticas", marquant bien ainsi la pluralité qui émane des acceptions du moi nérudien, directement lié à l'expression de ces poétiques, dans ses textes de critique aussi bien que de poésie. Le premier article relève le caractère évolutif des trois prologues du Caballo verde para la poesía de 1935, écrits lors du séjour de Pablo Neruda en Espagne en qualité de consul, et allant du programme poétique à la revendication d'une éthique annonçant le Canto general (1950). Le critique aborde toutes sortes de paradoxes, ainsi dans l'article intitulé « La materia como metalenguaje en la poesía de Pablo Neruda", où, partant de l'idée répandue de l'autosuffisance, de l' « intransitivité » du langage décrétée par la critique des années 60 , l'auteur défend au contraire, en plusieurs points, en rappelant l'omniprésence de la matière dans l'œuvre nérudienne, la transformation de cette dernière en langage, ce qui induit un "geste métapoétique " spécifique, et ce dès les trois Residencias en la tierra. En "naturalisant " le langage, en le "déshabitant", en le fondant en une maison poreuse et vivante, le poète réfléchit sa poésie et fait œuvre métapoétique, parvenant ainsi à ancrer le poème dans le monde. D'où, certainement, les nuances importantes de l'article intitulé «Pablo Neruda : la poética de los objetos ", basé sur deux postulats, par ailleurs démontrés par le critique tout au long de son œuvre : d'une part la matière comme objet idéologique marxiste -, d'autre part la matière comme lieu de l'inhabité. Entre les Residencias et les prologues de Caballo verde para la poesía est défini un passage des objets " anonymes " aux objets « humanisés » (p. 82) : « las superficies usadas, el gasto que las manos han infligido a las cosas, la atmósfera a menudo trágica y siempre patética de estos objetos, infunde una especie de atracción no despreciable hacia la realidad del mundo ». Par la 
suite seront définis l' "objet idéologisé », l'objet «naturel », l'objet " poématique ». C'est dans les poèmes nés des circonstances de la guerre civile espagnole dans Tercera residencia (1947), que les objets s'idéologisent tout d'abord, la main de l'homme et le travail y laissant leurs traces, puis dans le Canto general et dans les Odas elementales (1952-1954) ainsi que dans les Nuevas odas elementales (1956). Les objets "naturels" résultent d'une activité de l' "inhabité ", et Alain Sicard insiste particulièrement sur les diverses modalités et valeurs de l'objet " pierre ». L'objet poématique pour sa part, en vient, entre les « Artes poéticas » de Fin de mundo (1969) et Las manos del día (1967-1968), à passer de l'objet produit par le poète et marqué d'une utilité revendiquée, au rêve d'une «reabsorción dentro del mundo objetivo » (p. 94), le poème demeurant « una pregunta sin respuesta » (p. 95). Complétant cet article, le suivant, intitulé «La palabra silenciosa (para una poética de la piedra en la obra de Pablo Neruda) », définit le poème telle une pierre comme voix silencieuse d'un son ayant pris forme. La dimension politique de la poésie est bien sûr revisitée elle aussi dans l'article intitulé « Poesía y política en la poesía de Pablo Neruda » (p.105). Les différentes étapes idéologiques du poète $(1936,1956)$ y sont évoquées, de la modernité à une postmodernité qu'induirait un «septicismo histórico" (p.120) dans les années 1960-1970, lui-même partie prenante, peut-être, de la forme dialectique globale de la «modernidad » nérudienne, ce qui est objet de débat.

\section{Dialogues et itinéraires}

5 «Lecturas cruzadas » constitue une partie extrêmement dynamique dont le principe consiste, dans chaque article, en la confrontation de Pablo Neruda et d'un autre poète ; cette section se compose de cinq contributions dont trois ont une forme fragmentée apparentée à des notes de lecture, dont l'une est narrative puis analytique, et au centre desquelles vient s'insérer un article de forme plus classique, qui compare les rythmes des poésies maritimes de Rubén Darío et de Pablo Neruda sous le regard de Meschonnic, pour qui, rappelle l'auteur, «el ritmo no es una totalización del sentido, sino una infinitización ». De leur côté, les trois textes fragmentés, ainsi que le texte narratif, mettent en présence des faits, des analyses, des citations et le lecteur demeure passionné par ces juxtapositions fécondes sur le plan de la critique, parfois drôles, parfois discrètement lyriques, qui associent Walt Whitman, Nicolás Guillén, César Vallejo, Miguel Hernández et Pablo Neruda. Un simple exemple parmi de nombreux autres, met en regard des photos de Miguel Hernández et de Pablo Neruda: « En la cara del primero, la sonrisa es un sol inmenso. Una lluviosa melancolía envuelve al segundo »(p. 163).

6 La section intitulée "Navegaciones y regresos ", réfléchit dans un premier article sur les relations entre Pablo Neruda et l'Europe puis, dans un second article, sur celles de Pablo Neruda et de l'Andalousie; dans l'évocation de ces liens à l'Europe, la géographie est «réabsorbée par un espace culturel». La relation à l'Europe est bien sûr plus générale que l'autre, mais se centre sur l'Espagne, en particulier autour des années 1934-1937, entre mémoire de l'histoire ancienne -celle de la Reconquête-, histoire contemporaine, mémoire culturelle, et influences littéraires (Alonso de Ercilla, Quevedo, Villamediana...), et découverte, à distance, d'une identité américaine. La seconde relation évoquée est essentiellement littéraire, puisque le poète n'a séjourné 
que quelques heures de sa vie à Cadix. Elle connecte principalement Pablo Neruda à Rafael Alberti et à Federico García Lorca.

7 Enfin, "Variaciones en torno a dos poemas » reprend la présentation analytique fragmentaire que nous avons indiquée plus haut, pour évoquer deux poèmes, l'un extrait de la deuxième Residencia (1931-1935), l'autre de La Barcarola (1967), puis pour multiplier les occurrences de références à des thèmes proches, dans l'œuvre nérudienne, de ceux des poèmes cités, ainsi la mort, pour le premier d'entre eux. Il s'agit là encore de se laisser porter par les connexions proposées par Alain Sicard, qui sont à la croisée de récits vécus, de références mises en relation, de citations transposées sur le mode d'un collage, de passages analytiques ou plus brefs. La lecture pose de nouveau, comme un élément incontournable, la question de l'identité du sujet, et interroge en dernier lieu, avec humour, une possible postmodernité de l'œuvre nérudienne, la définition de la notion même de postmodernité n'étant pas tranchée...

8 Ainsi en cinq grands temps et par touches successives, mais aussi par approches variées, nous voyons revivre tout un pan de la vie du poète chilien, ses multiples engagements, et nous parcourons son œuvre, émanation d'une profondeur selvatique originelle et de la conscience du temps entassé et caché dans les pierres ; l'entrée de la voix dans le mouvement de l'histoire conforte cette conscience première du temps. L'émergence du moi poétique et son identification progressive au monde, que révèlent les analyses réunies dans El mar y la ceniza, enrichissent les réflexions du lecteur sur la notion essentielle de l'identité du sujet poétique, et, certainement, sur son propre rapport au monde.

\section{AUTEURS}

\section{BÉNÉDICTE MATHIOS}

Université Blaise Pascal/Clermont-Ferrand II 